Increasing HIV testing uptake in an inner city sexual and reproductive health clinic: a simple and effective method

Public Health England published a report on HIV in the UK in 2013 to coincide with the national HIV testing week (22-29 November 2013). ${ }^{1}$ The report stated that more than $20 \%$ of the 98400 people living with HIV in the UK remain unaware of their 


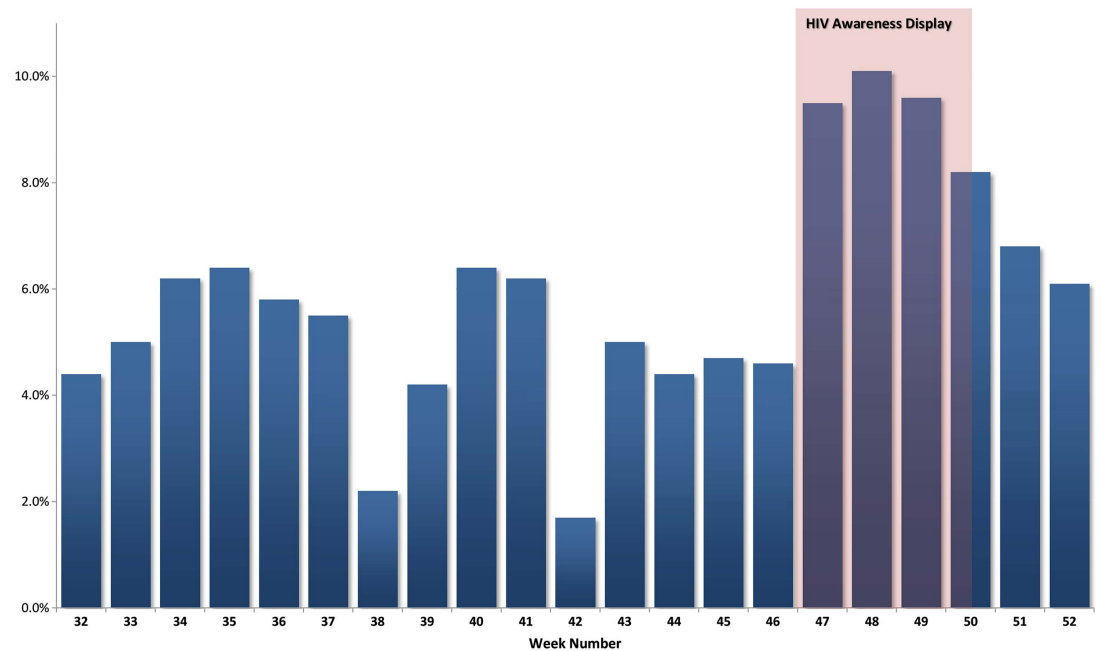

Figure 1 The national HIV testing week ran in Week 48. Our advertising display was visible in the waiting room during Weeks 47-50.

infection. Early HIV diagnosis is essential for better treatment and survival. Increasing the availability of testing has been proposed as a way to reduce the undiagnosed population. ${ }^{2}$ However, even where tests are available, achieving good uptake rates is vital.

We introduced a new advertising campaign to coincide with the HIV testing week in an inner-city sexual and reproductive health clinic in an area of high HIV prevalence (HIV prevalence of 2.7 per 1000 individuals aged $15-59$ years). This campaign involved the use of large visual aids in the waiting room, highlighting the availability and importance of HIV testing. HIV testing was always offered routinely as part of sexual health screening to clinic attendees, but uptake of the HIV test was normally low. We noted that during the presence of the HIV testing awareness display in the clinic waiting room, the uptake of HIV testing increased from an average of $4-5 \%$ of all attendances per week to $8-10 \%$ per week. The numbers appeared to drop back to the baseline rate in subsequent weeks, when the campaign posters were removed, as illustrated in Figure 1.

There could be several factors that influenced this rise in uptake. One factor could be that having a display in the waiting room seeded the idea of HIV testing in the minds of patients even before they entered the consultation, such that they were more accepting of the test when it was offered to them. A second factor could be that increased advertising made patients feel that this was a test collectively offered to everyone and so reduced any feelings of them being judged or singled out. A third factor could be that advertising positively affected staff attitudes when offering testing.

This work shows that the uptake of HIV testing in sexual and reproductive health clinics can be increased, albeit modestly, with a simple and inexpensive media display. The evidence would suggest that whilst the use of mass media health campaigns in isolation is rarely effective, the use of media in health promotion can be useful as part of a broader strategy. In particular, such messages can be effective when awareness-raising is important, and the change in behaviour is a simple one (in this case merely to accept a test). ${ }^{3}$ This type of intervention for HIV testing can easily be implemented in other settings, such as emergency departments, acute medical units and general practice. We would argue that such an intervention is a cost-effective and efficient method for increasing HIV testing uptake.

\section{Kanchana Seneviratne, MBChB, MRCP}

Specialist Registrar, Genitourinary Medicine, Department of Genitourinary Medicine, Nottingham University Hospital NHS Trust, Nottingham, UK; kanchanaseneviratne@doctors.org.uk

\section{Charlotte Porter, MRCOG, MFSRH}

Consultant, Sexual and Reproductive Health, Department of Sexual Health, Nottingham University Hospital NHS Trust, Nottingham, UK; Charolotte.Porter2@nuh.nhs.uk

\section{Ruth Taylor, MRCP, MFSRH}

Consultant, Sexual Health, Department of Sexual Health, Nottingham University Hospital NHS Trust, Nottingham, UK; ruth.taylor@nuh.nhs.uk
Competing interests None.

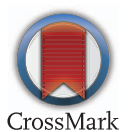

J Fam Plann Reprod Health Care 2014;40:314-315. doi:10.1136/fprhc-2014-101054

\section{REFERENCES}

1 Public Health England. HIV in the United Kingdom: 2013 report. November 2013. http://www.hpa.org.uk/webc/HPAwebFile/ HPAweb_C/1317140300680 [accessed 4 June 2014].

2 British HIV Association, British Association for Sexual Health and HIV, British Infection Society. UK National Guidelines for HIV Testing 2008. http://www.bhiva.org/documents/ Guidelines/Testing/GlinesHIVTest08.pdf [accessed 4 June 2014].

3 Health Development Agency. The Effectiveness of Public Health Campaigns. June 2004. http:// www.emcdda.europa.eu/attachements.cfm/att 94034_EN_Effectiveness\%20of\%20Mass\% 20Media\%20campaigns\%20HDA.pdf [accessed 4 June 2014]. 